\title{
Different Professional Ideal Types in the Inter- sectoral Management of Psychiatric Healthcare Trajectories
}

\author{
Jesper Frederiksen \\ Senior associate lecturer/Docent \\ University College Absalon, Centre for Nursing, Denmark \\ jefr@pha.dk \\ Mette Bonde Dahl \\ Associate lecturer/Lektor \\ UCL University College, Nursing and Occupational therapy, Denmark \\ mbda@ucl.dk \\ Kim Jørgensen \\ Associate lecturer/Lektor \\ UC Diakonissestiftelsen, Denmark \\ kimj@ucdiakonissen.dk
}

\section{Abstract}

Aim: To investigate how differences in types of professions and rationalities affect the management of inter-sectoral trajectories in psychiatric health care in the Capital Region of Denmark.

Background: Some psychiatry users experience a lack of coherence between the mental health care treatment provided at hospitals and run by the regions, and that provided at residential psychiatric units run by municipalities. The literature points to various challenges in this field of research, related to transitions that need rethinking and further examination.

Method: The approach is an eclectic use of theory and methods in a theory-governed analysis of empirical data built up from focus group interviews with professionals in mental health care centres and social psychiatric residencies. We classify the positions from the data using a theoretical framework based on Max Weber's theory of ideal types and from Pierre Bourdieu's concept of habitus. Our analysis outlines a theory about the practice of transitions in inter-sectoral trajectories in psychiatric health care.

Results: From the empirical material, we were able to construct different professional ideal types related to mental health care psychiatry and social psychiatry. The construction points to differences in the habitual basis of action that maintains institutional distinctions.

Discussion: Differences in ideal types are connected to the prevailing positions of the two sectors, in which management in health care centres follows a dominant medical rationality, and management in residencies draws on a social and social educational legitimacy. 
Conclusion: We find differences between the rationalities and habitus of staff at regional hospitals and municipal residencies that enable us to explain how management contributes to trajectories in psychiatric health care. Choices concerning trajectory transitions relate to a combination of habitual professional inclinations and the management of trajectories streamlined through illness classification based on a neoliberal governance model. Future management must be aware of the different rationalities linked to professional and institutional logics when planning; and this requires reflexivity and awareness of the management of intersectoral collaboration.

Key words: Habitus, Ideal types, Intersectoral trajectories, Management, Psychiatry, Transition

\section{Introduction}

In this article, we aim to investigate how differences in types of professions and rationalities affect the management of intersectoral trajectories in psychiatric health care in the Capital Region of Denmark. An initial presumption, picked up from speaking to psychiatry users from a user association prior to the investigation, was that some psychiatry users experience a 'wall' between mental health care treatments at regional centres and social psychiatric residential units. Our presumption is that the 'wall' describes a lack of coherence in intersectoral transitions in trajectories within psychiatric health care. Improving continuity or coherence in health care trajectories has been an explicit aim in Danish municipal and health care reforms since the 1980's (Frederiksen \& Olivares, 2017; HolmPetersen \& Sandberg Buch, 2014). The intention is a part of a greater puzzle with the purpose to improve cost control by larger units, increase efficacy by standardisation, and a relatively close management of the health professionals. The effort is one of several strategies related to the neoliberal management or governance regime (Frederiksen, 2019).

Inspired by the critical tradition of praxeology, we have developed a framework that enables us to understand and explain intersectoral psychiatric trajectories as a practice dependent on the attitude and opinions articulated. The contribution enables insight and knowledge of the social and symbolic dimensions of transitions and differences between the primary and secondary health care systems, which is of great importance to the understanding of those who work in the psychiatric health care system. In this article, we focus on a delimited area of a data set of interviews involving both psychiatry users and professionals, taken from a project on transitions in psychiatry - delimited, since we only examine the statements of the professional workers.

\section{Background}

In recent decades, the concept of transition has developed as an important international term in the social and health sciences in general, and in nursing research more specifically, related to the way people respond in life and health to a range of possible changes over time (Meleis, 2010;

Schumacher \& Meleis, 1994; Kralik, Visentin \& Van Loon, 2006).

A recent review of concepts and models of continuity of care in mental health services indicates that the clarification of care continuity may enable nurses working as care coordinators to develop a better understanding of their role (Weaver, Coffey \& Hewitt, 2017). Patients' opinions of transitions in health care trajectories in general, and in the field of psychiatry in particular, are sparse, though the awareness of generic crises caused in patients by psychiatric hospitalization is well known from earlier days (Aroian \& Prater, 1988). Even today, research on involvement in nursing handovers points to the need of rethinking the way nursing handovers involve psychiatry users (Olasoji et al. 2018). 
Studies on management and organization, especially from the area of elderly care, support intersectoral collaboration as a way towards improvement of intersectoral transition (Simpson et al. 2006). Magnusson and Lützen (2009) point to the need of ways of establishing joint responsibility in collaboration between psychiatric care and community social services, to improve the situation for people in the community with long-term mental illnesses. Cranwell, Polacsek and McCann (2017) urge improved care planning and coordination, in particular facilitating transitions for service users between tertiary medical and primary care service, as a way of improving care in this area.

Noseworthy et al. (2014) emphasize how important partnerships and the building of relationships between outpatient health care professionals are to a successful discharge planning process and the transition to outpatient clinics in community care. Improving guidelines for staff handovers in mental health care is a persistent theme in literature as well (Cowan et al 2018; Abdela-Dimech \& Vuksic, 2018), though a lack of attention to consumer preferences at handovers, despite the introduction of recovery-orientated models for mental care, is a problem (Waters et al. 2015). Mathiesen et al.

(2016) conclude that handover meetings primarily function as a way of organizing the clinicians' work and in some settings directly block user participation, and that research on experience gained from service user involvement in handovers indicates an area that needs rethinking and further examination (Small et al. 2017; Olasoji et al. 2018).

Thus, research points to the necessity of rethinking workflow, guidelines, coordination and collaboration in order to improve intersectoral transitions. Not many studies have taken a closer look at the significance of the structures within which management works, or to the action taken by professional agents when managing. This article aims to contribute to the latter.

\section{Approach used in this article}

In addition to the literature referred to, we claim that in our investigation we have been able to identify notable differences in the rationalities of staff at regional mental health care centres, and those employed at social psychiatry residential units. Though differences in institutional culture, tasks and settings do not necessarily lead to a lack of coherence and problematic transitions, we found quite remarkable differences in attitudes, opinions and articulations among professionals. This led to the development of a theoretical framework inspired by notions from critical praxeology and sociology that enabled an analysis of the material with a focus on professional types of rationality and legitimacy. Although these articulations miss an investigation of the agents' history and background and therefore are not performed as the praxeologic tradition indicates, we considered it as important to challenge this type of empirical data, by the approach of a theory-governed analysis using terms from this tradition as well as the Weberian tradition.

We find this approach relevant to nursing management due to the considerable political focus on coherence in health care trajectories in Denmark, as well as in other countries, due to ongoing changes in welfare state services brought about by pressures from demography, financial constraints and new treatment options. The professional care manager might well be a nurse, and this requires an awareness of intersectoral collaboration to build relationships across institutions, sector boundaries and professionals.

In this article, we firstly present the method and considerations related to data collection, and then build up a theoretical framework based on Max Weber's classical notion of ideal types and rationalities, and secondly add Pierre Bourdieu's notion of habitus for a scoping analysis of the data material. Thirdly, we present the findings of our reading of the narrative statements in order to understand the four different ideal types as a basis for the construction of habitus. Fourthly, we discuss and explain the results in relation to related theses and the aim of this article and present further considerations of the approach in the article itself. Fifthly, we conclude and summarize the implications for nursing management. 


\section{Theory and method}

The worldview of the investigation is a constructivist tradition of social science that takes a theoryguided approach to the processing of data. The framing and approach used in this article is a theorybased analysis of empirical data. Theory is limited to terms from Pierre Bourdieu's praxeology, and from Max Weber's theory of Ideal Types. The over-all aim of praxeology is to understand and explain the symbolic or hidden side of the external appearance of social practices. The aim of research within this tradition is to build up a theory of practice based on empirical data (Bourdieu, 2007). In the present case, we examined how the staff experienced intersectoral transitions between mental treatment healthcare (in a regional setting) and social psychiatric residencies (in a municipal setting), using group interviews. This collection of data did not embrace the theoretical approach in this article, as the dataset was collected from a phenomenological or hermeneutic approach (Flick, 2018; Halkier, 2006). However, the focus on vulnerable groups used by Bourdieu (1999) and the possibility of better insight called for theoretical terms to lift the processing of empirical data afterwards. We chose to collect data in focus group interviews because we were interested in the collective understanding of transitions in trajectories at the different institutions. Accordingly, we approached the interviews using general thematic categories and then re-examined the material through our theoretical lens. This eclectic way of working with data and selected theory does not allow an in depth analysis from a praxeologic perspective, and so does not compare to a well-planned Bourdieu study, but we claim that it shows a path to how the very strong analytical praxeologic tools can be brought to life in a range of combination studies. We will first describe the process of data collection, and then the theoretical framework constructed for the analysis.

\section{The group examined}

Overall, we did 11 focus group interviews for the project, involving professionals and psychiatry users from mental health care units in a regional setting, and from social psychiatric residential units in a municipal setting. We selected five focus groups of professional participants, with a total population of 20 , for further processing and analysis in this article (fig.1).

\begin{tabular}{|l|l|l|l|}
\hline $\begin{array}{l}\text { Focus group } \\
\text { IW number }\end{array}$ & Context & Participants & Professions \\
\hline A & $\begin{array}{l}\text { Mental health centre in- and } \\
\text { outpatient A }\end{array}$ & 6 & $\begin{array}{l}4 \text { ward nurses } \\
1 \text { nurse } \\
1 \text { social worker }\end{array}$ \\
\hline B & $\begin{array}{l}\text { Mental health centre in- and } \\
\text { outpatient B }\end{array}$ & 3 & $\begin{array}{l}2 \text { nurses } \\
1 \text { social worker }\end{array}$ \\
\hline C & $\begin{array}{l}\text { Mental health centre in- and } \\
\text { outpatient C }\end{array}$ & 3 & 3 nurses \\
\hline D & $\begin{array}{l}\text { Social psychiatry residence } \\
\text { municipality D }\end{array}$ & 4 & $\begin{array}{l}2 \text { nurses } \\
1 \text { occupational therapist } \\
1 \text { social educator }\end{array}$ \\
\hline E & $\begin{array}{l}\text { Social psychiatry residence } \\
\text { municipality E }\end{array}$ & 4 & $\begin{array}{l}1 \text { nurse } \\
1 \text { social educator } \\
2 \text { social and health care assistants }\end{array}$ \\
\hline & Number of participants & 20 & \\
\hline
\end{tabular}

Figure 1: Composition of interviews and the profession of participants 
The focus groups were recruited by contacting the leader in charge of the mental health centre and the manager of the social psychiatry residential unit, and we sent out written information of the study in advance. Then, an appropriate time for the interview was scheduled. We decided to base recruitment to the focus groups on the day-to-day organization of the units, relying on when the units were able to supply volunteers, and we had no influence on the composition of the groups. As figure 1 shows, the population consists mainly of nurses from the mental health care psychiatry centre, and groups with a more varied professional background from the social psychiatry residential units. Furthermore, one mental health care centre chose to put together a group of four ward nurses. In terms of our investigation, this might just be a coincidence; we did not find it random, but rather an expression of the kind of variation in rationalities that we intend to investigate further. We found that the pattern of group compositions corresponded to staffing patterns at the institutions. Our only requirement concerning the composition of groups was a size of 3-6 participants, and the five groups of professionals fulfilled this requirement. To access the institutions, one of the authors with a long experience of working in the field used his network to plan arrangements. This was essential for us to access the field.

\section{Focus group interviews}

We completed the interviews in focus groups supported by a thematic guide based on desk research done by the research group.

\begin{tabular}{|c|c|c|}
\hline Theme & Moderators action & Helping question \\
\hline Presentation & Frame setting & $\begin{array}{l}\text { Time, recording, aim, } \\
\text { confidentiality }\end{array}$ \\
\hline Experiences & Encourage examples & $\begin{array}{l}\text { How do you experience the way } \\
\text { the psychiatry users are } \\
\text { handled? }\end{array}$ \\
\hline Trust & Encourage examples & $\begin{array}{l}\text { In which situation is it important } \\
\text { to be counted on? }\end{array}$ \\
\hline Relatives & Encourage examples & $\begin{array}{l}\text { Who do you consider as relatives } \\
\text { and how are they involved? }\end{array}$ \\
\hline Communication & Encourage examples & $\begin{array}{l}\text { When is it especially important } \\
\text { to listen to the psychiatry user? }\end{array}$ \\
\hline \multirow[t]{2}{*}{ Continuity } & Encourage examples & $\begin{array}{l}\text { How do the first themes } \\
\text { influence continuity? }\end{array}$ \\
\hline & Small summary & \\
\hline Structure & Encourage examples & $\begin{array}{l}\text { Describe how the inter-sectoral } \\
\text { trajectories are planned - and } \\
\text { how they are completed }\end{array}$ \\
\hline Organisation & Encourage examples & $\begin{array}{l}\text { Recount your part in the last } \\
\text { welcome or discharge you } \\
\text { remember. What worked? What } \\
\text { did not work out? }\end{array}$ \\
\hline Transition & Encourage examples & $\begin{array}{l}\text { How are you working with the } \\
\text { management of care for the } \\
\text { psychiatry user? Or the place } \\
\text { from where the user arrives? }\end{array}$ \\
\hline \multirow[t]{2}{*}{ Coherence } & Encourage examples & $\begin{array}{l}\text { Do you have suggestions that } \\
\text { could improve coherence in the } \\
\text { trajectory? }\end{array}$ \\
\hline & Summary and validati & \\
\hline $\begin{array}{l}\text { Additional comments or } \\
\text { corrections }\end{array}$ & & $\begin{array}{l}\text { What would you like to add or } \\
\text { say? }\end{array}$ \\
\hline
\end{tabular}

Figure 2: Interview guide for the group of professionals 
The guide consisted of questions related in the first place to personal and individual matters, and then turning to the institutional or organizational level. The guide was tested and adapted after two pilot interviews involving a mixed group of professionals within a mental health care centre and a group of psychiatry users from a patient association. We used the interviews to adjust the interview guide. We conducted the interviews using pairs of moderators with primary and secondary roles, so that they could complement each other and encourage participants to elaborate on their experiences and opinions. Each interview lasted for one hour and was subsequently transcribed and anonymized. This resulted in 110 pages of full-text material. In figure 2 , we list the themes and a preliminary order of interview content, and as a help we developed questions for the beginning of each theme (Flick, 2018).

\section{The theoretical framework}

In our initial review of the literature, we identified a need for rethinking workflows (guidelines, coordination and collaboration), in order to improve intersectoral transitions. However, existing approaches are mainly functionalist, with an individual focus, and few studies approach the way management works in practice as structures linked to institutional and professional patterns and inclinations. To grasp the organizational content of management and position of the professions in relation to intersectoral trajectories, we turned to Weber's theory of ideal types as an important contribution that is still valid in the analysis of organizational management. However, we found a lack of individual understanding and sensitivity to group dynamics in action, which is something that would facilitate the further analysis of the connection between the ideal type and the orientation of trajectory management. We then supplemented the theoretical framework using the notion of habitus from Bourdieu.

Bourdieu states that meanings, attitudes and positions are due to circumstances and individual dispositions, and when these bodily-embedded dispositions and experiences, called habitus, go to work in social action, they express a 'practical sense'. Habitus is a product of history, and as such produces both individual and collective practice from experience. This means that experience becomes actual in present practice and establishes a connection to the principles of action in practice (Bourdieu 2007, p.91-95). However, a limitation in this article is that habitus cannot be derived from the present or past terms alone, but only compared with the social circumstances where it is active (Ibid, p.96). This is a weakness to the data set used for this article and a limitation to the range of analysis, but a very common problem in most qualitative research traditions. Despite this, we try to challenge the material by using the eclectic grip to incorporate theory from Weber.

In a review of Bourdieu-based management and organizational studies, Sieweke (2014) points to a devoid of the notion of habitus. The sensitivity brought in by habitus as a theoretical term would be a relevant contribution to further insight; as Wacquant points out, the current solution would appear to be a delimited use of Bourdieu's analytical terms (Wacquant, 2018). Thus, in this article, we allow us to desist from more extensive use of the Bourdieuan field-analysis

When a certain expression of rational thinking is under negotiation, for example in a focus group with other professions, participants recount and explain their experience in order to create either a common understanding or a disagreement. In both cases, they draw on basic principles and orientations, which may involve a certain degree of compliance related to the profession. This is not because the individuals think or act in the same way, but rather because of similarities in their backgrounds, educational choices, and present positions. Within professional groups, for example, this appears as a collective type of habitus (Bourdieu, 2007, p.100-102). It is important to understand the content of meaning and the basic values, and there is a distinction between the actual understanding and the explanatory understanding, whether in groups or individuals. This point emphasizes something of importance to us when we read the interviews, namely, to highlight an 
interest and focus on differences. From a Weberian point of view, we can recognize the orientations as more or less rational, and as subject to different orientations of rationalities (Weber, 2003, p.314).

In this way, it is possible for us to analyse this as connected to different theoretical orientations, organized, for example, as ideal types. According to Max Weber, the ideal type is "a conception that enhances certain qualities at the cost of others, constructed by the researcher for comparative purposes" (Månson, 2005, p. 110, authors' translation).

Weber describes four types of rationality as a pointer to how humans achieve certain legitimacy. Legitimacy is what gives the leader the right to exercise his dominion.

The first type is the traditional orientation of action, i.e. controlled by tradition or ingrained habits. This is followed by traditional legitimacy. The second type is the affective orientation of action, i.e. an orientation based on the actor's affects and emotions. This type is followed by charismatic legitimacy. The third type is the value-rational orientation of action, i.e. orientation derived from a conscious belief based on ethical, aesthetic or religious values independent of the effects of action. This is followed by value-rational legitimacy. The fourth type is the aim-rational orientation of action, i.e. action performed to achieve certain goals, in relation to which the actor calculates which actions are most effective. This type is followed by aim-rational legitimacy (Månsson, 2005, p. 96-100).

These four types of legitimacy are the basis of ideal-typical ways of orientation and, as we claim in our model, a suitable theoretical framework for a further explanation of professional action.

\section{The analytic strategy when using the framework}

From the selected elements of theory, we developed the conceptual framework (fig. 3) prior to reading the interviews. Each of the four ideal types has a window in the Weberian model, and habitus is built in as the explanatory link between non-rational and rational action.

Rational action

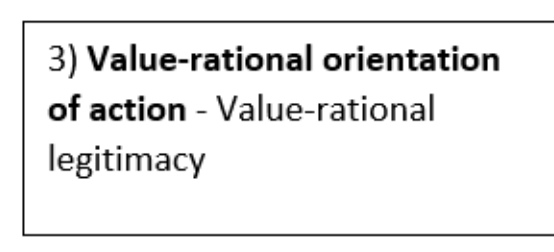

4

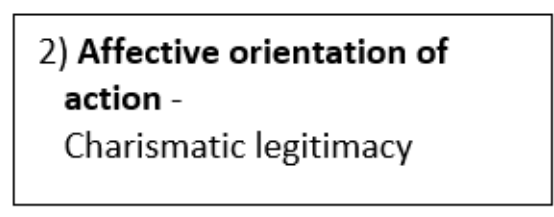

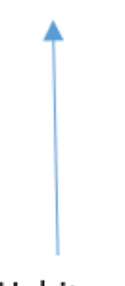

Habitus

\section{4) Aim-rational orientation of action -}

Aim-rational legitimacy

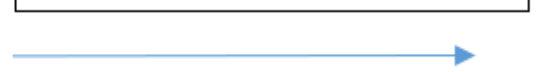

1) Traditional orientation of action -

Traditional legitimacy

\section{Non rational action}

Figure 3: Theory frame of orientation of ideal types after M. Weber and habitus as link to different fundaments of action (Månson, 2005, Bourdieu, 2007) 
We read the five interviews separately and coded the most significant statements according to the four orientations. After reading, we validated the findings in the research group by comparing our findings when reading, and then gathered the content in the shape of the most prevalent opinions. Subsequently, we presented the findings at a seminar to which the participating professionals, psychiatry users and other interested parties were invited, and later at an event for international students. The feedback we received led to minor adjustments of the material, and for each orientation, we shaped a compressed description based on the significant opinions assessed through the lens of the ideal type theory, to produce the results of the first part of the analysis.

Therefore, we chose compressed dissemination as suitable for illustrating the most prominent ideal-typical positions, aware of the reduction thus forced on the material. However, we found it acceptable as material for the following analysis and interpretation of the connection between the four orientations.

\section{Ethical considerations}

We carried out the research according to the provisions of the Danish Code of Conduct for Research Integrity (Ministry of Higher Education and Science, 2014). No formal permit from an ethics committee was required according to Danish legislation, as the purpose of the research was not to influence the informants, either physically or psychologically, and no biological material of any kind was collected. We obtained the permission from the manager of the health care centre or residential unit. The participants gave their informed consent after receiving verbal and written information about the purpose of the study. This included the information that withdrawal of participation was possible at any time, with no consequences, that all interviews where transcribed anonymously and that the sound file would be erased afterwards. With regard to interviews with staff, we had no further considerations. We applied for mandatory permission from the Danish Data Protection Agency, and had the project approved (file number 2017-41-5191). The study was funded by University College Capital in Denmark (today, University College Copenhagen) and publishing was made possible by Absalon University College. There are no conflicts of interest.

\section{The findings and analytical construction}

The statements in the processed material pointed towards different rationalities and legitimacies connected to the professional group and the institutional logic within mental health care psychiatry and social psychiatry. In the following presentation, we present the orientations through the lens of our framework. We merge a significant sample of the coded statements from the 110 pages of interviews into the compressed descriptions or ideal-typical pictures, and subsequently link the positions to a stipulated construction of habitus. The descriptions are discursive representations of the social practice around the interview situation and represents the interpretations of the professionals. These descriptions are part of the social structure, but far from the entire structure (Frederiksen, 2017), as we have previously pointed out as the limitation of this eclectic approach. Finally, we sum up the rationalities and positions of the two sectors of psychiatric treatment in fig. 4.

\section{Orientation 1: Traditional orientation of action}

We have some systems that pose certain challenges ... we have a way of organizing ourselves ... few resources ... and some work schedules that must be followed, and contact persons (IW A). We don't know enough about each other's workflow or resources ... But when homecare tells us that they need 
five days to prepare to receive a patient, well - and I'm not saying this to criticize either homecare or the patient - this is not the best way to meet the patient's desire to return home (IW A).

Another weakness is the frequent staff changes and lack of personnel continuity (IW A).

As primary therapists, we use the cognitive model. In this way our conversations [with psychiatry users] are structured and we make sure that our notes agree [for the documentation], so they are structured... you know... by an agenda... since the last meeting,... what topics have to be on the agenda, things we have to look up, and whatever else - depending on the medication (IW B).

Here, we have psychoeducation as an offer to the relatives in parallel sessions...so the relatives have their sessions and the young people have theirs [to cope with the treatment] (IW B).

The OPUS-concept [Cognitive Analytic Therapy, treatment model for young people with a psychosis] is a little different [from the usual] because we all work in the same way... I don't know if this is always the best, I mean... some patients would actually be better off having a social worker if there are many social issues. Likewise, some would be better off with a physiotherapist or nurse (IW B). Where is the health professional in all this? It's mainly social educators and unskilled staff [talking about the staff at the residential units] and this can complicate the dialogue (IW C).

We have done some work on absences and no-show, so how much responsibility have the patients themselves to get help? (IW C). I can feel that the patients are calmer when we have good contact with their relatives. At several of the residential units they [the staff] are simply afraid of some patients... they [the patients] sit there screaming and suddenly a member of staff says: 'He's too ill, we must get him hospitalized.' But the people at the emergency ward, they say: 'Well now, look here, he is in residential care ... you've accepted him, so you have to solve it.' So, the patient comes back to us - and it's just ping-pong backwards and forwards (IW C). (Translation by the authors.)

\section{Orientation 2: Affective orientation of action}

You try to collaborate with them [the psychiatry users] about what makes sense to them, for example their housing, drugs, and so on (IW D)... we can't force people to take something they don't want... unless a treatment order has been made, you can decide for yourself... (IW D). ...this is a 'home'. They can go anywhere... [Despite security plans]. It's all about small steps to learning some skills, being persistent, and working with the resident's relations. We are working on motivation, the wishes of the residents - it is not our needs that must be met, but their needs (IW E). It's all about us having to meet the residents ... where they are at..., and not just on the basis of a diagnosis or a treatment order... I think it is a beautiful thought... them coming here because they have the need of support and structure (IW E).... it's a work with huge motivation... it's about what is meaningful to the residents. Every single day... (IW E).

Talk about continuity and user participation does not necessarily make sense... when working with... let's take a resident who has just moved in. There might be a hundred good reasons for reading all the documentation that follows the patient, for example statements from a hospital ward or a municipality, or action plans, or whatever. However, there may be good reasons for not reading all this in order not to be prejudiced to the patient, but rather to form your own impressions of them (IW D)... knowing too much can be an obstacle to creating a relationship ... this is how we should meet the residents when they move in (IW E).

I was at a discharge meeting at the hospital yesterday, and-err-my expectation when I got to the meeting was that the patient would be present ... you know, the resident who was supposed to be moving in to us ...but in fact, the meeting was in a room with seven people present, but not the patient... and it was said that they had chosen not to tell him, or bring him in, because he couldn't stand being in a room with so many people. Well, although I don't have much experience with such 
cases, my expectation was of course that he needed to be present or at least know that we were there and that he could meet us (IW D). (Translation by the authors.)

\section{Orientation 3: Value-rational orientation of action}

We are employed to provide relational care no matter what our educational background - of course, we can draw on our professional skills, but most of all I do relational work (IW D). As long as the residents are oriented and thrive, it is up to them whether they want to take part in these plans or not [individual plans of action] (IW D). Relational workers are those who visit the resident on a daily basis and help with correspondence, remembering dentist appointments, and so... and handing out medicine...one of our tasks might be to administer medicine, order more of it and receive it from the visiting psychiatrist ... patients often don't want to see the psychiatrist ... they would rather avoid them and escape ... so with all with possible errors in mind, we have to coordinate things, like when patients get one kind of medicine from their GP for an infected sore, or something else from the hospital, and then the psychiatrist comes along and makes changes (IW D.)

For various reasons, some patients have a treatment order, and this has been activated, so they are hospitalized... in these cases we see quite good cooperation between social psychiatry and treatment psychiatry in the shape of what is called 'focused management'... when we call them and want an order activated, it is important that our request is complied with... residents can overreact and get aggressive. So good cooperation helps ... when they throw things at us, we need to know how much is needed to get a verdict activated (IW E). But the main task is to support and structure everyday life, and some patients get well enough to move on into more independent housing ... but some don't have any network because they have been so ill and psychotic or challenged... and here we can help them and perhaps establish some form of contact (IW E).

The ethics are important... to think of the ethics when using the documentation system available... is it ethically okay to note and pass on to colleagues information given to me by another human being? There are things you must document and things you have to act on... but in the system, it's a mess. For example, in my previous employment a young man told me he was deeply unhappy he had never had a girlfriend or slept with a girl. This was information given in trust to me, but it becomes a problem when written down in the system - and I could never dream of doing that (IW D).

(Translation by the authors.)

\section{Orientation 4: Aim-rational orientation of action}

The psychiatric treatment model is evidence-based, and it has been decided at the regional level that we should work with cognitive therapy as supplement to medicine (IW A). We work with 'CAT' [Cognitive Analytic Therapy] which means we have tried to implement a CAT-folder in which the patient has his aims described... and how we work on this, and so on...however, an audit has shown that patients don't use the CAT-folder (IW A).

We work with a 'case-manager', who of course follows the entire trajectory... we discuss the trajectory planned for the individual... and then there are different groups: psychoeducation of patients and 'social-skills training groups' (IW B). We know from evidence that the more knowledge both relatives and patients get, the better chances they have to recover (IW B). We use a blackboard to structure the week for the patients and plan the quite extensive programme of activities - and the staff chosen as contacts are the leaders who coordinate and follow up the agreements made with the users (IW A).

We have a discharge group once a week and a patient guide for discharge. However, in a current case where both father and son need treatment at home, there are 25 visits from professional workers every week and this demands massive coordination (IW A). 
To enter OPUS you must be newly diagnosed in the F20 spectrum... this means schizophrenia, schizotypal disorders, psychosis of some sort... and preferably not been receiving sufficient medical treatment for more than six months before coming here... and our criteria state that they should preferably not have any abuse problem, because this is contraindicated if we are going to work cognitively (IW B).

The descriptions of patient trajectories used by the Region are followed here, which means that the patients are divided into five types (new, seen, unstable, stable, ready for discharge) to ensure progress in treatment. If five new patients are arriving, we must find types four and five among those we have and get the process speeded up (IW C). The treatment we offer is aimed at the 'normal group', so what if someone is more seriously ill? Because many beds have been closed down and patients are living at home, they are in a difficult situation, despite all good intentions and patient trajectory descriptions. Recovery?... they are so ill, and many have very severe abuse problems. [However, this is not our task.] (IW C) (Translation by the authors.)

\section{Analytic construction}

When building up compressed descriptions from coded statements, the construction of the empirical data suggests a traditional orientation of action (orientation 1) and an aim-rational orientation of action (orientation 4) that are mainly to be found at the mental health care centres. In contrast to this, the social psychiatric residential units reveal mainly an affective orientation of action (orientation 2) and a value-rational orientation of action (orientation 3). This indicates differences between the legitimacies of action of health professionals and social educational professionals. It also points to a relatively large gap in rationality between the two sectors, served by different professionals that may cause failure in transition and the quality of trajectories for psychiatry users, which is pointed out in the initial literature review.

In our theoretical framework (fig. 3) the connection made by habitus between non-rational and rational action is vertically connected to the logic of sectors. We find psychiatric treatment at the regional mental health care centres situated on the right-hand side of the model, and the municipal social psychiatric residential units on the left-hand side of the model. In Bourdieu's words, the representation of habitus in collective professional action establishes a connection to the principles of action in practice.

The experience of the professionals becomes actualized in present practice, and what they may call apparently obvious patterns of actions are closely related to their institutional and professional ideology and logic.

This means that action on trajectories at the regional mental health care centres, seen as idealtypes in action, appears to follow an administrative aim-rational legitimacy, and is linked to an embedded non-rational (and subconscious) traditional legitimacy. This type carries a collective habitual inclination, expressed from the position of management in alliance with cognitive and evidence-based treatment, which aims to achieve efficiency in models, systems and methods. From a medical point of view, the aim of this approach is to cure as many patients as possible using the resources available. This includes teaching psychiatry users as well as their relatives how to cope with treatment, abuse abstinence, specific diagnosis codes and compliance with the structure of daily living, mental therapy and physical training.

On the other hand, action on trajectories at municipal social psychiatric residential units is built up as ideal types, following in action a value-rational legitimacy, and embedded in non-rational (and subconscious) affective charismatic legitimacy. This type of legitimacy carries a collective habitual inclination expressed by positions that emphasize activity and quality of life as important to the psychiatry user, to maintain practical as well as intellectual skills. The aims of this approach are 
articulated as inclusion and rehabilitation for re-entering the community - predominantly using an approach through dialogue and motivational support to find meaningfulness and to cope with life.

In other words, analysis within our theoretical framework reveals the contexts of the residential units and the mental health care centres as two sectors in which professional staff build on quite different rationalities and orientations of action, and in which managements are guided by different legitimacies. In this analysis, these differences are found to be expressions of variations in habitual inclination related to transitions in psychiatry users' trajectories.

In fig. 4, we visualize the summary of the analysis in relation to the framework, and name the ideal types based on the rationalities from the theoretical framework.

\section{Rational action}

\begin{tabular}{|c|c|c|}
\hline $\begin{array}{l}\text { Social Psychiatry Residential } \\
\text { Units/Municipal }\end{array}$ & & $\begin{array}{l}\text { The Mental Health Care } \\
\text { Centers /Regional }\end{array}$ \\
\hline $\begin{array}{l}\text { 3) The Idealists } \\
\text { Order of maintenance through } \\
\text { dialogue } \\
\text { Activity and quality of life } \\
\text { Pedagogical and social aim: to } \\
\text { include } \\
\text { Humanist approach } \\
\text { 2) The Sensitive }\end{array}$ & Habitus & $\begin{array}{l}\text { 4) The Operators } \\
\text { Order of efficiency through } \\
\text { systems and methods } \\
\text { Cognitive and medical } \\
\text { evidence based treatment } \\
\text { Medical aim: to cure } \\
\text { Bio-medical approach } \\
\text { 1) The Retainers }\end{array}$ \\
\hline
\end{tabular}

Non-rational action

Figure 4: The rationalities and positions of the two sectors of psychiatry

At the regional health care centres, traditional legitimacy as a non-rational 'retainer' seems to work as a basis for the aim-rational legitimacy of the 'operator' in the management of trajectories. At the social psychiatry residential units, charismatic legitimacy as a non-rational 'sensitive' seems to work as a basis for the value-rational legitimacy of the 'idealist' in the management of trajectories. In addition, we build up the relationship between the sectorial ideal types condensed through three typical positions from the material. These positions we summarize as follows: at the mental health care centre we find a bio-medical approach, the medical aim of curing, cognitive and medical evidence-based treatment, and efficiency through systematic methods. At the social psychiatric residential units, the positions summarized are a humanist approach, a psychoeducational and social aim, using activity to increase and maintain the quality of life and through dialogue. 


\section{The discussion of key findings and considerations}

In this discussion, we explain the key findings and results of our analytical construction presented in fig. 4. We investigate the construction of ideal types and significant positions in relation to related theses and the article's aim. We further present methodological considerations of the approach in this article.

\section{Treatment within a neoliberal regime of management}

The analytical construction based on data from focus group interviews points, as indicated, to a distinction between rationality and legitimacy in the two sectors that we are able to demonstrate to some extend by a theory-governed analysis of the data. It is a consequence of various historical developments in different professional groups, as well as the last 25 years of contemporary neoliberal management and governance within the public sector. Management systems of this type are built into the health care system in order to increase efficacy, and in alliance with rational medicine and so-called evidence based systems, they have dominated the public sector in Denmark in recent decades (Frederiksen \& Olivares, 2017; Frederiksen, 2019). The management approach called neoliberal management, or governance, works by classification and sorting, and is, in Wacquant's words, liberal and laissez-faire towards the top of society, but paternalistic and punitive towards the bottom of society (Wacquant, 2009).

The connection between the regional psychiatric health care system and municipal social psychiatry offers general health care and support to a vulnerable and weak group, in which people are suffering from more serious mental disorders. They often end up at the bottom of society, either because their disorders are connected to conditions of social deprivation, or due to the common fact that these mental disorders are stigmatizing and lead to social isolation. Findings in our material point to further sorting supported by the medical choice of treatment, in which cognitive models are selected to get the best effects and results, while more psychodynamic and environmental therapeutic methods are rejected by the region in charge of the treatment of these groups. Standardized evidence based trajectories work as governance in psychiatric health care and are pulled down over everyday experiences and living conditions from a perspective of paternalism and biomedicine (Jørgensen, 2019). Based on this medical treatment logic, treatment is offered to the least mentally ill, who show the best treatment results, whereas the most ill are excluded from treatment. These people are too ill to live alone in their own homes, and since no further offer of treatment exists besides medicine, they are sent to social psychiatry provision in the municipalities, where they can stay at residential units to recover. The findings point to a systematic change from a health and treatment package towards a social and educational offer of maintaining the quality of life. However, this is not articulated 'up front' to psychiatry users who live in residential units, in the hope of and belief in recovery and cure.

\section{Everyday life in psychiatry and allocation of opportunities}

The transition in trajectory between sectors is a question of professional management on a structural and organizational level; as the literature initially points out, there are various perspectives on the transition issue. The transition in trajectory is connected both to organizational structures and to institutional rationalities, and embedded in the orientation of the habitus of the professions as well. These points align somewhat with a study by Petersen (2013), who from a new-institutional and ethnographic approach finds similar and different everyday logics in both residential units and hospitals. Here, everyday life on a micro level is identified as more differentiated than our theoretical framework indicates. The everyday logics described are user resources, consequences, medicine, 
care, customers, and the community of employees (in our case, the professions). We recognize these logics in our material. However, we claim that differences in why these everyday logics coexist on the basis of different approaches and are backed by different legitimacies, may only be explained by understanding structures as related to different rationalities, founded in habitual inclinations, embedded in for example groups of professionals. However, our material and the eclectic methods puts some limitations on further examination of these structures because we only have the discursive representations and not the knowledge on the history and background of the professionals (nor the patients/residents). If this had been available and part of the examination, the praxeology framing could have provided an empirical stepping stone to understand how the positions in the different sectors are not equal, but structures of more or less dominating positions constituting a social order or classification of practice within a class dominance of overall and subordinate relations. This type of tension between biomedicine as dominant and controlling, and social educational action as supportive is examined in relation to families in need of welfare services for children with disabilities in several studies. Carlhed (2007) shows how child habilitation over time is enveloped in a medical perception; and Horne (2016) points out the distribution of capital in the families as important to understanding the support assigned to the children. Horne points to a paradox similar to that found in our material, namely that the less privileged and needing the families are, the more difficult it seems to be to get the care they need. The most vulnerable do not speak the language of the funders, and they are not aware of the importance of the right diagnosis codes and medical statements, which are essential for granting of adequate assistance. They are pigeonholed into other levels of service and may be punished for not to living up to their role as parents. This agrees with Wacquant's description of how the neoliberal regime works in actu.

\section{Trajectory management as professional classification and education}

We find that a structural similarity to psychiatry occurs in our material in cases where the management of transitions in psychiatric healthcare trajectories seems to work on different principles in different sectors. In the Regional sector, sorting takes place after a diagnosis suited for the evidence-based model or not, no matter who the patients are: strong or weak, curable or chronic, clean or in abuse, young or old.

Re-education focuses on cost-efficient treatment and cure in cases where therapy is meant as a (mandatory) offer for both psychiatry users and their relatives, following different approaches to what is known as psychoeducation. In the municipal residential units, the management of transition in psychiatric trajectories seems to be adjusted to residents' wishes, maintaining individual preferences, and to respect the residents. Psychoeducation has a focus on including the resident within the residential unit and in society, and various activities focus on increasing the individual quality of life.

Thus, strategies in Mental Health Care and in Social Psychiatry follow different approaches and rationalities, and it seems likely that when residents become 'patients' and vice-versa they must overcome the shift in rationality in addition to their mental disorder. Ideal typical action relates to sectors and institutions, as well as to professions. The habitual and historical connection of nurses to medicine can be seen as an explanation of the strong position enjoyed by aim-rational and traditional legitimacy at regional mental health care centres. It is not quite so obvious how the nurse transforms into relational workers in residential units. In our focus groups, we have a composition in which nurses are present, but take up very different positions to nurses at mental health care centres. They follow an affective and value-orientated rationality that is similar to institutional legitimacy. This emphasizes that neoliberal management and governance work in practice by shaping the institutional habitus that we can identify here at the sector level. When a nurse identifies herself as a relational worker, this articulates a joint collaborative position at residential units that reflects a 
social and social educational conception of equality between staff and residents, as well as between different professions among the staff. We believe the nurses mean what they say, but it is nevertheless an expression of governance through institutional discursive governance.

This is also the case at mental health care centres, where professionals other than nurses work as equals, for example as contacts to the psychiatry users, but specificity in tasks concerning treatment, medicine and management place the nurses in a central position in relation to the dominating doctors. Regardless of what type of 'equalizing systems' are common in the psychiatry sector, they do not involve the medical doctors, who have their own doctor contact system.

The absence of medical doctors as a permanent feature in the residential units is possibly an amplifying explanation as to why these institutions do not follow the same rationality and legitimacy as the regional sector. Here, the system is more hierarchically articulated because of an arbitrary historical development, which has given medical doctors the right to define the practice and treatment as biomedicine, so that they do not work on an equal footing with other staff. Thus, findings on collaboration coincide with research emphasizing that inter-collaboration is reserved to the dominated professions performing with equivalent professional groups, while those in a dominating position maintain order and their own status (Frederiksen, 2016, 2017).

\section{Methodological reflections}

When nursing researchers look into their own field of practice and make interviews with a majority of informants that have the same educational, social and cultural background, the process is in many ways problematic. At the time when our study was launched, all of the authors were colleagues on the nurse-training programme and did in this way take a position in nursing. One author had broad experience of psychiatric nursing, which gave him an important role as a gatekeeper to make the interviews possible, because of a practice that is somewhat closed and protective for many good reasons. One author had no experience of psychiatry and one had experience as a relative over a long period of time. In the research group, we did reflect on and discuss our positions vis-à-vis the research field, as well as our own perceptions. The study was established as an exploratory investigation, and this carried in itself a risk of transferring to it notions of practice. However, by talking to both staff and psychiatry users, we did change to produce a fairly complex image. We experienced that inputs from pilot interviews with the user association, and from the later seminar, were very informative contributions. The inclusion of informants from the professions was very random, as it was not possible to select participants. We had to accept the composition of groups as they were if we wanted the interviews, and here we only had 'semi-professionals', like nurses, and others with similar training. This is of course not representative, as informants refer a lot in the interviews to both medical doctors and to unskilled workers. It would have been relevant to include the doctors as well as the unskilled workers. Here, dominance and symbolic power goes both ways, because staff are not eager to involve doctors, and they tend to be reluctant to voice criticism when doctors are present. In addition, staff told us that it is very difficult to get doctors to take part in qualitative research done by researchers who are 'semi-professionals'. The nurses do apparently not include unskilled workers because they are not considered to carry important knowledge. In this way, the inclusion and exclusion of informants is a finding on its own account.

The execution of focus group interviews from an open, explorative thematic guide provided us with the general body of material. However, from the perspective of praxeology, this could have contributed to a more extensive construction, if empirical data had been collected more specifically in order, for example, to construct types of capital with a view to the construction of habitus from the individual level. In the present analysis, the concept of habitus is used as a tool to understand and link orientations, rather than actually reconstructing habitus on an individual level. We find it 
possible to use the notion in this way but are aware that this means a reduction in the scope of the concept.

\section{Conclusion}

In this article, we have made a theory-govern analysis of statements from interviews with professionals from the Mental Health Care and the Social Psychiatry. The investigation had focus on how differences in professional types and rationalities affect the management of intersectoral trajectories in psychiatric health care in the Capital Region of Denmark. Although many efforts are pronounced in order to strengthen coherence in the health care trajectories to psychiatry users, we find differences between the rationalities and habitus of staff at regional hospitals and the municipal residential units that enable us to understand them as a management practice in this area. We can stipulate sectoral orientations as connected to habitual inclinations embedded in the professional and institutional habitus. The trajectory transitions seem to be connected to habitual professional inclinations, in which the management of trajectories aligns with a neoliberal governance model. We are cautious not to point out orientations as we emphasize the orientations are ideal typical constructions made for analytical purpose by the researchers. However, we underline the preserving and maintaining character of each of these orientations, as they do not seem to solve the transitional problems facing psychiatry users. We do also find a distinct system of classification or sorting of psychiatry users that is worth discussing from the perspective of human ethics and calls for reflection on how health care services should contribute to the care of some of the most vulnerable people in society. When planning, future management should be aware of the different rationalities linked to professional and institutional logics, and this requires reflexivity and awareness in the leadership of intersectoral management and collaboration.

\section{Acknowledgements}

We would like to thank associate professor Tanja Thinggard Andersen and associate professor Astrid Reinhardt Birch Nielsen from the Psychomotor Training department of University College Copenhagen who contributed to the pilot study. Also, former programme manager, Simon Simonsen, from the Health Research Programme at UCC, who supported the project. Participants at The international writing seminar at IUC, Dubrovnik, have kindly given critical feedback. We moreover sincerely wish to thank the psychiatry users and the professionals who participated in the study for their interest, and for taking time to share their thoughts and experiences. 


\section{References}

Abdela-Dimech, F. \& Vuksic, O. (2018). Improving the practice of handover for psychiatric inpatient nursing staff. Archives of Psychiatric Nursing, 32: 729-736, doi.org/10.1016/j.apnu.2018.04.004

Aroian, K., \& Prater, M. (1988). Transitions entry groups: Easing new patients' adjustment to psychiatric hospitalization. Hospital and Community Psychiatry, 39, 312-313, doi: 10.1176/ps.39.3.312

Bourdieu, P. (1999). The Weight of the World. Cambridge: Polity Press.

Bourdieu, P. (2007). Den praktiske sans [Le sens pratique]. Copenhagen: Hans Reitzels forlag.

Carlhed, C. (2007). Medicinens lyskraft och skuggor - om trosföreställangar och symbolsk makt i habiliteringen 1960-1980 [The glow and shadows of the Medicine: Doxa and symbolic power in the area of services to young children with disabilities 1960-1980]. Ph.D.-thesis. University of Uppsala.

Cowan, D., Brunero, S., Luo, X., Bilton, D., \& Lamont, S. (2018). Developing a guideline for structured content and process in mental health nursing handover. International Journal of Mental Health Nursing, 27: 429-439, doi:10.1111/inm.12337

Cranwell, K., Polacsek, M. \& McCann, T.V. (2017). Improving care planning and coordination for service users with medical co-morbidity transitioning between tertiary medical and primary care service. Journal of Psychiatric and Mental Health Nursing, 24: 337-347, doi: 10.1111/jpm.12322

Engström, L. (2012). Klinikken flyttar hem - Sjuksköterskans institutionella praktik inom specialiserad palliativ hemsjukvård [The clinic moves home: nurses' institutional practice in specialised palliative homecare] Ph.D.-thesis. Uppsala: University of Uppsala.

Flick, U. (2018) An Introduction to Qualitative Research, Sixth edition. Thousand Oaks: Sage

Frederiksen, J. (2016). Tværprofessionelle velfærdsprofessioner - Tværsamarbejde som en social praktik for den neoliberale velfærdsstats professioner [Interprofessional Professions of Welfare: Inter-collaboration as a Social Practice for the Professions of the Neoliberal Danish Welfare State]. Ph.D.-thesis. Roskilde: University of Roskilde.

Frederiksen, J. (2017). Strategier for tværsamarbejde sætter professionsidentiteter under pres [Strategies of inter-collaboration puts professional identities under pressure]. Tidsskrift for Arbejdsliv 19 (2): 57-73, doi.org/10.7146/tfa.v19i2.109072

Frederiksen, J. (2019). The Jigsaw Puzzle of Governance by Soft terms in Healthcare: Capturing the Neoliberal Impact of Health Policy on Nurses' Work. Praktiske Grunde - Nordisk tidsskrift for kultur-og samfundsvidenskab. 13 (1-2): 7-24.

Frederiksen, J. \& Olivares, B. (2017). Coherence in the Danish Healthcare System: The Endavour of Governing Healthcare. Praktiske Grunde - Nordisk tidsskrift for kultur-og samfundsvidenskab. 11 (3-4): 21-40.

Halkier, B. (2006) Fokusgrupper [Focus groups]. Frederiksberg: Samfundlitteratur.

Holm-Petersen, C. \& Strandberg Buch, M. (2014). Litteratur om ledelse af samarbejde på tværs af sektorer $i$ sundhedsvæsenet [Literature on management of inter-sectoral collaboration in the Healthcare system]. Copenhagen K: KORA.

Horne, R. (2016). Like barn leikar best - en praxeologisk studie om habilitering av hjelpetrengande barn og unge [Birds of a feather flock together: a praxeology study on habilitation of children and adolecents in need of help] Ph.d.-thesis. Bergen: Bergen universitet. 
Jørgensen, K. (2019). Mulighedsbetingelser for patientinddragelse og recovery i psykiatrien [Potential conditions for patientparticipation and recovery in psychiatry] Ph.D.-thesis. Institut for Mennesker og Teknologi. Roskilde: Roskilde Universitet.

Kralik, D., Visentin, K., \& van Loon, A. (2006). Transition: A literature review. Journal of Advanced Nursing, 55(3): 320-329, doi: 10.1111/j.1365-2648.2006.03899.x

Magnusson, A. \& Lützen, K. (2009). Factors that influence collaboration between psychiatric care and CSSs: experiences of working together in the interest of persons with long-term mental illness living in the community. Scandinavian Journal of Caring Sciences, 23: 140-145, doi:10.1111/j.14716712.2008.00600.x

Meleis, A.I. (ed.) (2010). Transitions Theory - Middle-Range and Situation-Specific Theories in Nursing Research and Practice. New York: Springer Publishing Company.

Ministry of Higher Education and Science. (2014). Danish Code of Conduct for Research Integrity. Copenhagen: Ministry of Higher Education and Science.

Mathiesen, V., Obstfelder, A., Lorem, G.F. \& Måseide, P. (2016). User participation in district psychiatry. The social construction of 'users' in handovers and meetings. Nursing Inquiry, 23 (2): 169-177, doi: 10.1111/nin.12127

Månson, P. (2005). Max Weber. In H. Andersen \& L.B. Kaspersen (eds.) Klassisk og moderne samfundsteori [Classical and Modern Social Science Theory], third edition, pp.90-111. Copenhagen: Hans Reitzel.

Noseworthy, A.M., Sevigny, E., Laizner, A.M., Houle, C. \& La Riccia, P. (2014). Mental Health Care Professionals Experiences With the Discharge Planning Process and Transitioning Patients Attending Outpatients Clinics Into Community Care. Archives of Psychiatric Nursing, 28: 263-271, doi.org/10.1016/j.apnu.2014.05.002

Olasoji, M., Plummer, V., Reed, F., Jacob, S., Shaw, L., Shanti, M. \& Cross, W. (2018). Views of mental health consumers about being involved in nursing handover on acute inpatient units. International Journal of Mental Health Nursing, 27:747-755, doi: 10.1111/inm.12361

Petersen, A. (2013). Hverdagslogikker i psykiatrisk arbejde - en institutionsetnografisk unders $\varnothing$ gelse af hverdagen i psykiatriske organisationer [Everyday-logics in psyciatric work] Ph.D.-thesis.

Doctoral School of Organisation and Management. Frederiksberg: Copenhagen Business School.

Sieweke, J. (2014). Pierre Bourdieu in management and organization studies - A citation context analysis of discussion of contributions. Scandinavian Journal of Management 30(4): 532-543, doi: 10.1016/j.scaman.2014.04.004

Simpson, E., Butler, M., Al-Somali, S., \& Courtney, M. (2006). Guiding the transition of nursing practice from an inpatient to a community-care setting: A Saudi Arabian experience. Nursing and Health Sciences, 8(2): 120-124, doi: 10.1111/j.1442-2018.2006.00258.x

Schumacher, K. L., \& Meleis, A. I. (1994). Transitions: A central concept in nursing. Journal of Nursing Scholarship, 26(2): 119-127, doi: 10.1111/j.1547-5069.1994.tb00929.x

Small, N., Brooks, H., Pedley, R., Gibbons, C., Lovell, K. \& Bee, P. (2017). Understanding experiences of and preferences for service user and carer involvement in physical health care discussions within mental health care planning. BMC Psychiatry, 17: 138, doi: 10.1186/s12888-017-1287-1

Wacquant, L. (2009). Punishing the poor - the Neoliberal Government of Social Insecurity. Durham: Duke University Press.

Wacquant, L. (2018). Fire tværgående principper for at bruge Bourdieu [Four transversal principals when using Bourdieu]. Praktiske grunde. Nordisk tidsskrift for kultur-og samfundsvidenskab, 12 (1-2): 5-20. 
Waters, A., Sands, N., Keppich-Arnold, S., \& Henderson, K. (2015). Handover of patient information from crisis assessment and treatment team to the inpatient psychiatric unit. International Journal of Mental Health Nursing, 24:193-202, doi: 10.1111/inm.12102

Weaver, N., Coffey, M. \& Hewitt, J. (2017). Concepts, models and measurement of continuity of care in mental health services: A systematic appraisal of the literature. Journal of Psychiatric Mental Health Nursing, 24: 431-450, doi: 10.1111/jpm.12387

Weber, M. (2003). Herredømmets typer (uddrag) [The Types of Legitimate Domination (excerpt) from Economy and Society, Part One: Conceptual Exposition], in Weber M. Udvalgte tekster [Selected texts], vol. 2, pp. 309-355. Copenhagen: Hans Reitzel. 